\title{
Analysis of the Relationship between Port Industry and Economic Growth Based on Cointegration Theory
}

\author{
Sun Jianping, Li Zhenfu, Chen Zhuo, and Liu Tongchao \\ College of shipping economics and management,Dalian Maritime University,Dalian,China
}

\begin{abstract}
The reciprocal covariance function between port Industry indicator and economic growth indicator is constructed according to time series, the cross spectral density between port industry indicator and economic growth indicator is obtained by Fourier transform after Yessentuki-Henning window truncation, and the correlation, coherence and leading lag relationship between port industry and economic growth were calculated by calculating the estimated values of mutual amplitude spectrum, coherence spectrum and phase spectrum. Then, the causality between port industry and economic growth is tested by cointegration theory, and the relationship between endogenous factors and exogenous variables is determined by impulse response and variance decomposition. The calculation results of the actual data show that the development of China's port industry and economic growth maintain a high degree of consistency in the length of 3 to 4 years and economic growth will lead the development of the port industry 0.8 years to 1.1 years. The results of dynamic econometric analysis show that China's port industry and economic growth are Granger reasons; China's port industry has made a negative response to economic growth. The economic growth has made a positive response to the impact of the development of the port industry, and the response has gradually increased with the passage of time; China's port industry and economic growth are affected by endogenous variables, and both of them affect each other in the course of development.
\end{abstract}

\section{Introduction}

In the process of economic development in a country or region, a very important characteristic is the export strategy of industrial products. Throughout the history of the western developed economies, from the beginning of the first industrial revolution to the present era of the information age, the import and export trade industry has played a significant role in promoting economic growth. As a carrier of import and export commodities, the port industry provides the possibility for the import and export trade in the world. Therefore, the relationship between port industry and economic growth is related through import and export trade, and the uncertainty of this relationship provides the direction for the research of this paper. At present, the research on the relationship between port industry and economic growth is lack of empirical evidence, or the empirical research is limited to simple data statistics, which does not fundamentally reveal the relationship between port industry and economic growth. Therefore, it is of great significance to clarify the relationship between port industry and economic growth.

Aiming at the uncertain relationship between port industry and economic growth, this paper uses spectrum analysis technology to decompose the time series of the two groups of indicators of port industry and economic growth into a series of frequencies representing the fixed-length cycle. The cross-spectrum is used to analyze and evaluate the correlation between the wavelengths of the two groups and the cross-spectrum analysis method between the port industry and the economic growth is established[2-4]to clarify the leading, lag and other related relations between the development of port industry and economic growth [3], at the same time, the intensity of the relationship between the port industry and economic growth is analyzed through the impulse response and variance decomposition, and the influence mechanism between port industry and economic growth is studied in depth.

\section{Cross - spectrum Analysis of Port Industry and Economic Growth}

\subsection{Cross - Spectral Analysis Model of Port Industry and Economic Growth}

For the different types of spectral analysis methods, the paper uses the cross-spectrum analysis method based on the Wiener-Khinchine theorem, which points out that the power spectral density of the wide stationary stochastic process is the Fourier transform of its autocorrelation function.

According to the theorem, it can be seen that the time series of cross spectral analysis based on Wiener-Khinchine theorem need to be stationary and 
stochastic, so it is necessary to smooth and randomize the time series.

For the time series $y_{t}$ after the smooth processing, we give the observation value of $\mathrm{n}$ samples, then the mathematical expectation is

$$
\mathrm{E}\left(\mathrm{y}_{\mathrm{t}}\right)=\mu_{\mathrm{y}}=\frac{1}{\mathrm{n}} \sum_{\mathrm{t}=1}^{\mathrm{n}} \mathrm{y}_{\mathrm{t}}
$$

The standard deviation is

$$
\mathrm{s}_{y}=\sqrt{\frac{1}{n-1} \sum_{i=1}^{n}\left(y_{t}-\mu_{y}\right)^{2}}
$$

The autocorrelation coefficient of the sample is $C(\tau)$

$$
\mathrm{C}(\tau)=\frac{1}{\mathrm{n}-\mathrm{k}-1} \sum_{\mathrm{t}=1}^{\mathrm{n}-\mathrm{k}}\left(\mathrm{y}_{\mathrm{t}}-\mu_{\mathrm{y}}\right)\left(\mathrm{y}_{\mathrm{t}+\mathrm{k}}-\mu_{\mathrm{y}}\right)
$$

The spectral density is obtained by Fourier transform of $\mathrm{C}(\tau)$

$$
Q_{y}(f)=\sum_{\tau=-M}^{M} C(\tau) e^{-j 2 \pi f \tau}
$$

Then, the Euler formula is then taken into the spectral density formula, we can get

$$
Q_{y}(f)=\sum_{\tau=-M}^{M} C(\tau)[\cos (2 \pi f \tau)-j \sin (2 \pi f \tau)]
$$

By using the stable characteristic of covariance and the correlation property of trigonometric function, we can get

$$
\mathrm{Q}_{\mathrm{y}}(\mathrm{f})=\mathrm{C}(0)+2 \sum_{\mathrm{k}=1}^{\mathrm{M}} \mathrm{C}(\tau) \cos (2 \pi \mathrm{f} \tau)
$$

As the development of port industry and economic growth can be expressed by variables or parameters, by selecting the indicator variables that can represent the port industry and economic growth to form a binary sequence, spectrum analysis technology is used to decompose the time series of the two groups of indicators of port industry and economic growth into a series of frequencies representing the fixed-length cycle, and the correlation between the wavelengths of the two groups is analyzed by the cross- spectrum, and the cross-spectrum analysis method between the port industry and the economic growth is established.

(1)Correlation and Cross Spectrum of Binary Sequences

1) Mutual variance function and cross spectrum density function

First, the port industry indicator time series $\left\{X_{t}\right\}$ and Economic growth indicator time series $\left\{Y_{t}\right\}$ constitute a set of binary sequences, and excluding all the trend factors in the data, its autocorrelation coefficient $\widehat{R}_{x y}(k)$, $\widehat{\mathrm{R}}_{\mathrm{yx}}(\mathrm{k})$ are formulae $(7),(8)$ :

$$
\begin{gathered}
\widehat{\mathrm{R}}_{\mathrm{xy}}(\mathrm{k})=\frac{1}{\mathrm{~N}} \sum_{\mathrm{t}=1}^{\mathrm{N}-\mathrm{k}}\left(\mathrm{x}_{\mathrm{t}}-\mu_{\mathrm{x}}\right)\left(\mathrm{y}_{\mathrm{t}+\mathrm{k}}-\mu_{\mathrm{y}}\right), \mathrm{k}=0,1,2, \cdots, \mathrm{M} \\
\widehat{\mathrm{R}}_{\mathrm{yx}}(\mathrm{k})=\frac{1}{\mathrm{~N}} \sum_{\mathrm{t}=1}^{\mathrm{N}-\mathrm{k}}\left(\mathrm{x}_{\mathrm{t}+\mathrm{k}}-\mu_{\mathrm{x}}\right)\left(\mathrm{y}_{\mathrm{t}}-\mu_{\mathrm{y}}\right), \mathrm{k}=0,1,2, \cdots, \mathrm{M} \\
\mu_{\mathrm{x}}=\frac{1}{\mathrm{~N}} \sum_{\mathrm{t}=1}^{\mathrm{N}} \mathrm{x}_{\mathrm{t}} \\
\mu_{\mathrm{y}}=\frac{1}{\mathrm{~N}} \sum_{\mathrm{t}=1}^{\mathrm{N}} \mathrm{y}_{\mathrm{t}}
\end{gathered}
$$

Among them, $\mu_{\mathrm{x}}, \mu_{\mathrm{y}}$ respectively represent the mathematical expectation of time series $\left\{X_{t}\right\}$ and $\left\{Y_{t}\right\}$, $\mathrm{N}$ is the length of time series, $\mathrm{M}$ is the maximum lag; The correlation structure between the port industry indicator time series $\left\{\mathrm{X}_{\mathrm{t}}\right\}$ and the economic growth Indicator time series $\left\{Y_{t}\right\}$ is described by the reciprocal covariance function $R_{x y}(k)$, the formula is (11):
$\mathrm{R}_{\mathrm{xy}}(\mathrm{k})=\operatorname{cov}\left(\mathrm{X}_{\mathrm{t}}, \mathrm{Y}_{\mathrm{t}+\mathrm{k}}\right)=\mathrm{E}\left(\mathrm{X}_{\mathrm{t}}-\mu_{\mathrm{x}}\right)\left(\mathrm{Y}_{\mathrm{t}+\mathrm{k}}-\mu_{\mathrm{y}}\right)$

Then, according to the correlation theory of spectral analysis, the spectral density function $[4] \mathrm{Q}_{\mathrm{xy}}(\mathrm{f})$ and the cross covariance function $\mathrm{R}_{\mathrm{xy}}(\mathrm{k})$ are subjected to the Fourier transformation of formula (12):

$\mathrm{Q}_{\mathrm{xy}}(\mathrm{f})=\sum_{\mathrm{k}=-\infty}^{\infty} \mathrm{R}_{\mathrm{xy}}(\mathrm{k}) \mathrm{e}^{-\mathrm{j} 2 \pi \mathrm{fk}}|\mathrm{f}| \leq \frac{1}{2}$

$\mathrm{Q}_{\mathrm{xy}}(\mathrm{f})$ is the cross-spectral density function, which represents the average of the product of the component with the frequency $\mathrm{f}$ both in the time series $\left\{\mathrm{X}_{\mathrm{t}}\right\}$ of the port industry indicator and the time series $\left\{Y_{t}\right\}$ of the economic growth indicator.

Thus, $Q_{x y}(f)$ reflects the correlation of the phase of time series $\left\{X_{t}\right\}$ and $\left\{Y_{t}\right\}$ at f.Since $R_{x y}(k)$ is real and is obtainable, $Q_{x y}(f)$ is also present atf $\epsilon\left[-\frac{1}{2}, \frac{1}{2}\right]$.

2)Co-direction spectrum and orthogonal spectrum

For the binary stationary time series composed of the time series $\left\{X_{t}\right\}$ of the port industry indicator and the time series $\left\{Y_{t}\right\}$ of the economic growth indicator, since $\mathrm{R}_{\mathrm{xy}}(\mathrm{k})$ is not an even function,so $\mathrm{Q}_{\mathrm{xy}}(\mathrm{f})$ is usually a complex function, then the true part and the imaginary part are respectively $\alpha_{x y}(f)$ and $\beta_{x y}(f)$, then $\alpha_{x y}(f)$ reacts to the relativity of the same direction frequency component of two time series, i.e., the co-direction spectra, $\beta_{x y}(f)$ reacts to the correlation of the heterogeneous frequency components of two time series, i.e. orthogonal spectra. The cross spectrum can be expressed as:

$$
Q_{x y}(f)=\alpha_{x y}(f)-j \beta_{x y}(f)
$$

When the time series of the port industry and economic growth are processed by Fourier transform, the relation between the whole time domain and the frequency domain is studied. But when using computer to process time series, it is impossible to measure and calculate infinite time series. So we usually select its limited time segment for analysis. In order to reduce the leakage of spectrum energy during the phase process, this paper uses Yessentuki-Henning window to truncate the time series of port industry and economic growth.

$$
\lambda(\mathrm{k})=\left\{\begin{array}{c}
\frac{1}{2}\left[1-\cos \left(\frac{2 \pi \mathrm{k}}{\mathrm{M}}\right)\right], \\
0
\end{array}\right.
$$

$\widehat{\mathrm{R}}_{\mathrm{xy}}(\mathrm{k})$ and $\widehat{\mathrm{R}}_{\mathrm{yx}}(\mathrm{k})$ are truncated by Henning window, and then the co-direction spectrum and orthogonal spectrum of $\left\{X_{t}\right\}$ and $\left\{Y_{t}\right\}$ are obtained by Fourier transform.

$$
\begin{aligned}
& \alpha_{\mathrm{xy}}(\mathrm{f})=\sum_{\mathrm{k}=-\infty}^{\infty} \frac{1}{2}\left[\widehat{\mathrm{R}}_{\mathrm{xy}}(\mathrm{k})+\widehat{\mathrm{R}}_{\mathrm{xy}}(-\mathrm{k})\right] \cos (2 \pi \mathrm{fk})= \\
& \frac{1}{2}\left[\widehat{\mathrm{R}}_{\mathrm{xy}}(0)+\widehat{\mathrm{R}}_{\mathrm{xy}}(0)\right]+ \\
& \sum_{\mathrm{k}=1}^{\mathrm{W}} \lambda(\mathrm{k})\left[\widehat{\mathrm{R}}_{\mathrm{xy}}(\mathrm{k})+\widehat{\mathrm{R}}_{\mathrm{yx}}(\mathrm{k})\right] \cos (2 \pi \mathrm{fk}) \\
& \quad \beta_{\mathrm{xy}}(\mathrm{f})=\sum_{\mathrm{k}=-\infty}^{\infty} \frac{1}{2}\left[\widehat{\mathrm{R}}_{\mathrm{xy}}(\mathrm{k})-\widehat{\mathrm{R}}_{\mathrm{xy}}(-\mathrm{k})\right] \sin (2 \pi \mathrm{fk})= \\
& \sum_{\mathrm{k}=1}^{\mathrm{W}} \lambda(\mathrm{k})\left[\widehat{\mathrm{R}}_{\mathrm{xy}}(\mathrm{k})-\widehat{\mathrm{R}}_{\mathrm{yx}}(\mathrm{k})\right] \sin (2 \pi \mathrm{fk})
\end{aligned}
$$

Where $\mathrm{W}$ represents the truncation point, the size of which affects the length of the selected time series.If W is larger, more sample data is included, will lead to the choice of $\mathrm{K}$ is too large, the curve peak is more, there are a lot of false peak, while the smaller $\mathrm{W}$ will lead to the choice of $\mathrm{K}$ is too small, the curve will be too smooth. So the selection range of the cut-off point is usually taken 
in $[2 \sqrt{n}, 3 \sqrt{n}]$, where $n$ is the number of observation values.

(2)Mutual amplitude spectrum, coherence spectrum and phase spectrum.

For the representation of complex numbers, the cross-spectral density of the time series $\left\{X_{t}\right\}$ of the port industry indicator and the time series $\left\{Y_{t}\right\}$ of the economic growth indicator can also be expressed by the polar coordinate notation, in addition to the formula (13) for:

$$
\begin{aligned}
& Q_{x y}(f)=\alpha_{x y}(f)-j \beta_{x y}(f)=A_{x y}(f) e^{j 2 \pi \phi_{x y}(f)} \\
& \text { Among them, } \\
& A_{x y}(f)=\left|Q_{x y}(f)\right|=\sqrt{\alpha_{x y}(f)^{2}+\beta_{x y}(f)^{2}} \\
& \qquad B_{x y}(f)=\left|Q_{x y}(f)\right| / \sqrt{Q_{x} Q_{y}}= \\
& \quad \sqrt{\alpha_{x y}(f)^{2}+\beta_{x y}(f)^{2}} / \sqrt{Q_{x} Q_{y}}
\end{aligned}
$$

$A_{x y}(f)$ represents the modes of the co-direction spectrum and orthogonal spectrum and it is called the reciprocal amplitude spectra, which reflects the relation between the amplitudes of each frequency component of the time series of the port industry indicator $\left\{\mathrm{X}_{\mathrm{t}}\right\}$ and the time series of the economic growth indicator $\left\{Y_{t}\right\}$. Due to the influence of the observed sequence values, the observed time series refers to the sequence of the different values of a certain indicator at different times, so the reciprocal spectral values of the two different time series are not comparable. $B_{x y}(f)$, which represents the coherence spectrum, is used to measure the consistency of the two sequences in frequency. $Q_{x}$ and $Q_{y}$ are the spectral density functions of the sequence $X_{t}$ and $Y_{t}$ respectively. The value of coherence spectral $B_{x y}(f)$ after coherence processing is in $[0,1]$, if the result is closer to 1 , it indicates that the correlation of the two sequences is higher, the consistency performance is better, conversely, if the result is far away from 1 , the correlation between the two sequences at this frequency is poor.

$\phi_{\mathrm{xy}}(\mathrm{f})$ represents the phase spectrum of the cross-spectral density, which reflects the phase difference between the time series $\left\{\mathrm{X}_{\mathrm{t}}\right\}$ and $\left\{\mathrm{Y}_{\mathrm{t}}\right\}$ at each frequency, that is, the leading and lag relationship between the two. For the time series $\left\{X_{t}\right\}$ and the time series $\left\{\mathrm{Y}_{\mathrm{t}}\right\}$, it is limited to a certain interval, such as $[-\pi, \pi]$, by observing the phase spectrum value of the two sequences in this interval, we can determine the leading and lag relationship between them.If $\phi_{x y}(f)$ is greater than 0 , then $\mathrm{x}$ is ahead of $\mathrm{y}$ and vice versa. By comparing the overall fluctuation of the two time series, the time difference between them can be well judged.

If the results of the observations of $\alpha_{\mathrm{xy}}(\mathrm{f})$ and $\beta_{\mathrm{xy}}$ (f)are brought into the formula (18), (19), (20), we can obtain the mutual amplitude spectrum $A_{x y}(f)$, coherence spectrum $B_{x y}(f)$ and phase spectrum $\phi_{x y}(f)$, then the atlas can be processed and analyzed.

\subsection{Implementation of Cross Spectral Analysis Method}

(1)Index extraction and data processing

1) The selection of indicators

Port cargo throughput is an important quantitative indicator reflecting the results of port production and operation, its fluctuation is the direct manifestation of the cyclical fluctuation of economic development in the port industry, therefore, the selection of port cargo throughput represents the development indicator of China's port industry. GDP as the final result of production activities of all habitual units of a country or region in a certain period is the most important basis to measure the economic health of a region in a country, and its change can represent the development of economy in different time, so its time series can be used as the index to reflect the change of China's economic growth. The indicators are summarized as shown in table 1 .

2) Basic methods of data processing

The use of the cross spectrum analysis method requires that the variable is a stationary time series, so the data collected will be tested for smoothness first, which is used in the ADF test ${ }^{[7]}$ in this paper. If the data shown after the test is non-stationary, then the data collected will need to be processed to be stabilized to meet the requirements of the spectral analysis method. According to the characteristics of the data used and the characteristics of each kind of time series processing methods, this paper uses the Hodrick-prescott filter method (hereinafter called H-P filter method) ${ }^{[5-6]}$ to separate the trend of time series, and extracts the factors

\begin{tabular}{|c|c|c|c|c|}
\hline $\begin{array}{c}\text { Indicator } \\
\text { type }\end{array}$ & $\begin{array}{c}\text { Indicator } \\
\text { name }\end{array}$ & Data unit & $\begin{array}{c}\text { Data } \\
\text { natur } \\
e\end{array}$ & $\begin{array}{l}\text { Time } \\
\text { quant } \\
\text { um }\end{array}$ \\
\hline \multirow[b]{2}{*}{$\begin{array}{c}\text { Indicator } \\
\text { sequence } \\
\text { of port } \\
\text { industry }\end{array}$} & $\begin{array}{c}\text { Cargo } \\
\text { throughput } \\
\text { of major } \\
\text { coastal } \\
\text { ports in } \\
\text { China }\end{array}$ & $\begin{array}{c}\text { Million } \\
\text { Tons }\end{array}$ & Year & \multirow{4}{*}{$\begin{array}{l}1985- \\
2014\end{array}$} \\
\hline & $\begin{array}{c}\text { Growth } \\
\text { rate of } \\
\text { cargo } \\
\text { throughput } \\
\text { of major } \\
\text { coastal } \\
\text { ports in } \\
\text { China }\end{array}$ & $\begin{array}{c}\text { Dimensi } \\
\text { onless }\end{array}$ & Year & \\
\hline \multirow{2}{*}{$\begin{array}{c}\text { Indicator } \\
\text { sequence } \\
\text { of } \\
\text { economi } \\
\text { c growth }\end{array}$} & $\begin{array}{c}\text { China's } \\
\text { gross } \\
\text { domestic } \\
\text { product } \\
(G D P)\end{array}$ & $\begin{array}{c}\text { Billion } \\
\text { Yuan }\end{array}$ & Year & \\
\hline & $\begin{array}{l}\text { China's } \\
\text { GDP } \\
\text { growth } \\
\text { rate }\end{array}$ & $\begin{array}{c}\text { Dimensi } \\
\text { onless }\end{array}$ & Year & \\
\hline
\end{tabular}
which contain only fluctuation and periodic component to carry on the cross-spectrum analysis. The processed data is then tested again to verify whether the data meets the requirements or not.

Table 1 Indicator selection summary table

Source: China Statistical Yearbook 
In terms of the port cargo throughput indicator and the GDP growth rate indicator included in the indicator setting, the growth rate of existence itself does not have the trend component factors, but considering that under the planned economy system of our country, the indicator of growth rate may have some trend effect, and the filtered data will fluctuate around the 0 axis, so it is easy to compare with other indexes when using cross spectrum analysis. Therefore, in order to ensure the validity of the final data processing results, H-P filter processing is also done for the relative indicators of growth rate in this paper. The results of the ADF test of the indicator sequence after $\mathrm{H}-\mathrm{P}$ filter processing are shown in Table 2.

Table 2. Statistics of ADF test results of the indicator sequences after H-P filtering

\begin{tabular}{|c|c|c|c|c|c|}
\hline $\begin{array}{c}\text { Indicator } \\
\text { sequence }\end{array}$ & t test & $1 \%$ & $5 \%$ & $10 \%$ & Prob. \\
\hline $\begin{array}{c}\text { Cargo } \\
\text { throughput of } \\
\text { major coastal } \\
\text { ports in China }\end{array}$ & -1.989 & -2.647 & -1.953 & -1.610 & 0.044 \\
\hline $\begin{array}{c}\text { Growth rate of } \\
\text { cargo } \\
\text { throughput of } \\
\text { major coastal } \\
\text { ports in China }\end{array}$ & -4.540 & -2.647 & -1.953 & -1.610 & 0.000 \\
\hline $\begin{array}{c}\text { China's gross } \\
\text { domestic } \\
\text { product } \\
\text { (GDP) }\end{array}$ & -3.610 & -2.665 & -1.956 & -1.609 & 0.001 \\
\hline $\begin{array}{c}\text { China's GDP } \\
\text { growth rate }\end{array}$ & -3.386 & -2.647 & -1.953 & -1.610 & 0.001 \\
\hline
\end{tabular}

It can be seen from table 2 that the time series of each indicator after $\mathrm{H}-\mathrm{P}$ filter processing passes the ADF test. Among them, the indicator of cargo throughput of major coastal ports in China rejects the original hypothesis at significant level $\alpha=0.05$, indicating that the probability of existence of single association is small in the sequence, and the other time series index test results show that it rejects the original hypothesis at the significant level $\alpha=0.01$, it can be considered that the filtered time series of indicators is in stable state and the cross-spectrum analysis can be done on them.

(2)Cross spectral analysis

The spectral analysis of the coherence spectrum and the phase spectrum between the port industry and the economic growth can be obtained by spectral analysis after filtering and passing through the time series after the stationary test, as shown in Figure 1 and Figure 2. According to the change of the graph, we can analyze the consistency and leading and lagging relationship between port industry and economic growth under different periods.

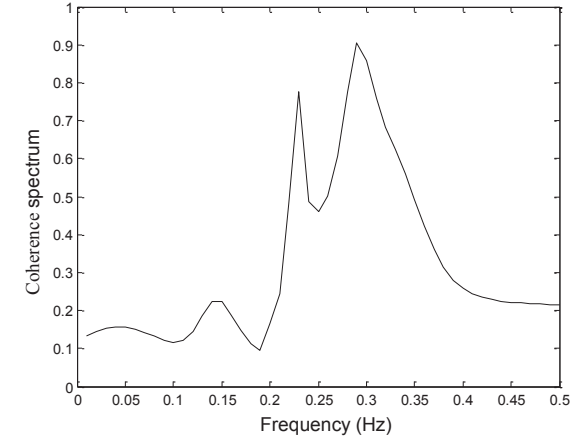

Fig. 1. Coherence spectrum of the throughput of major coastal ports and GDP of China

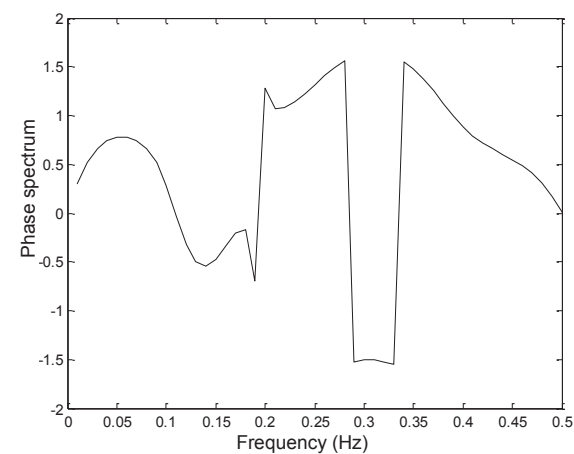

Fig.2. Phase spectrum of the through put of major coastal ports and GDP of China

According to the results shown in Figure 1, we can see that the coherence spectra value of the major coastal ports and GDP of China are higher at the frequencies of 0.23 and 0.28 , and are greater than 0.75 , so the consistency of the two sequences here is higher. As the reciprocal of the frequency indicates the length of the cycle, it can be analyzed and judged that the correlation between the development of China's port industry and the economic growth is high in the cycle of 3.57 and 4.45 years of length. The horizontal axis of the spectrogram shows the frequency, and the more the spectral graph is left, the smaller the frequency and the value of the coherence spectrum are, which can be used to analyze the long period of more than 10 years, the correlation between the development of port industry and the economic growth of China is small. Fig. 2 shows the phase spectrum of the throughput of the major coastal ports in China and of GDP. It can be seen that the values of the phase spectra at frequencies of 0.23 and 0.28 are 1.14 and 1.51, respectively, indicating that the GDP indicator representing economic growth is ahead of the throughput indicator representing the development of maritime industry. Among them, the period of length of 4.5 years and the period of the length of 3.7 years are respectively leading to 0.8 years and 0.86 years (time difference $=$ phase spectrum $\div 2 \pi \times$ cycle length). From the coherence spectrum and the phase spectrum of the throughput of the major costal ports and GDP of China, it can be seen that there is a mutual influence and interaction between the development of port industry and economic growth of China. 
Fig. 3 and Fig. 4 respectively indicate the coherence spectrum and phase spectrum between the growth rate of throughput of major coastal port and the growth rate of GDP of China.

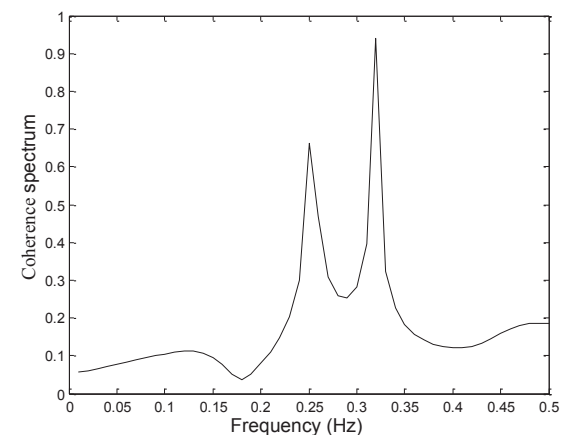

Fig. 3. Coherence spectrum of the growth rate of throughput of major coastal ports and of GDP of China

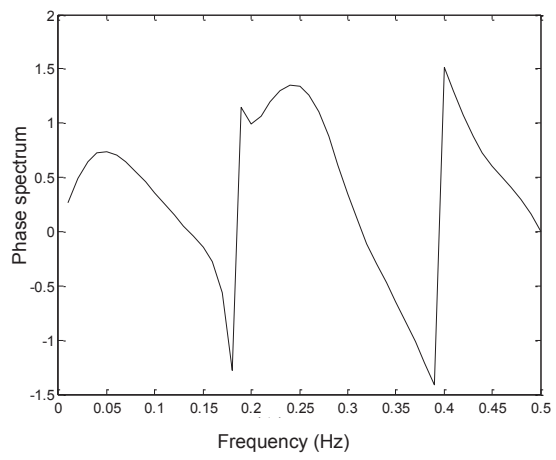

Fig. 4. Phase spectrum of the growth rate of throughput of major coastal ports and of GDP of China

The coherence spectra of Figure 3 show that the coherence spectra value of frequencies at 0.25 and 0.31 are significantly higher, that is, the growth rate of throughput of major coastal ports of China is higher than that of GDP in the period of 4 years and 3.13 years. But the frequency under 0.1 gradually tends to be gentle and the correlation degree is small, namely, the correlation degree between development of port industry and the economic growth of China is low in the period length over 10 years. It can be seen from the phase spectrum of Figure 4 that the phase spectra are 1.34 and 0.1 at frequencies 0.25 and 0.32 , and the phase spectrum is positive, that is, the growth rate of China's GDP is ahead of the throughput of the major coastal ports, and the leading length of time is 0.85 years and 0.05 years respectively.

\section{Dynamic Measurement Analysis of China 's Port Industry and Economic Growth}

The method of cross-spectrum analysis can be used to analyze the consistency and phase relationship between the development of port industry and economic growth of China through the analysis of coherence spectrum and phase spectrum, but the influence between the two is not determined by the interaction or one-way effect, and whether there is a causal relationship between the two, what the causal relationship is like is not determined, therefore, after doing the cross spectrum analysis, we need to further study the relationship between the two. This paper further explains the specific relationship between time series of the development of port industry and the time series of the economic growth of China through dynamic econometric analysis.

\subsection{Variable selection and data description}

When using cross-spectral analysis to analyze the consistency and the phase relationship between the development of port industry and the economic growth of China, the throughput indicator of major coastal ports and the GDP indicator of China from 1985 to 2014 are used, which respectively represent the main indicator of the development of ports industry and economic growth of China, in order to further analyze the causality between the two and the response of endogenous variables and external variables, the paper also uses the original data of throughput of the major coastal ports of China and GDP of China in 1985-2014 years in determining the cointegration relationship and the analysis of the impulse response and the variance decomposition.

\subsection{Cointegration and causality test of port industry and economic growth}

The development of port industry and economic growth will be influenced by many factors, such as the volume of world economy and trade, the input of labor force, the level of shipbuilding industry, the status of Port construction, the State policy, etc. To more accurately describe the relationship between the port industry and economic growth, first of all, it is necessary to test the stability of the throughput indicator of port industry and GDP indicator of economic growth of China, and to determine the number of integrated order of the unstable time series, so as to judge the possibility of cointegration test[11].The test results are shown in Table 3.

The test results from table 3 indicate that $\mathrm{CX}$ and $\mathrm{CY}$ are second-order single Integer I (2), which may have cointegration relationship, so the cointegration test is needed. The results of cointegration regression statistics are shown in table4.

The regression equation can be obtained by Table 4 : $\mathrm{CX}_{t}=1.795 \mathrm{CX}_{t-1}-0.7795 \mathrm{CX}_{t-2}+0.609 \mathrm{CY}_{t}+\varepsilon_{t}(21)$ The determination coefficient of the sample is $R^{2}=0.999016$, the final coefficient of the adjusted sample is $\bar{R}^{2}=0.998937$, and the D-W test statistic result is 1.722383 , the regression test of the second order sequence correlation does not have the pseudo regression phenomenon.

The unit root test results of $\varepsilon_{\mathrm{t}}$ are shown in Table 5 . 
Table 3. Unit Root Test Results for Indicator Sequence of China's Port Industry Development (CX) and Economic Growth (CY)

\begin{tabular}{|c|c|c|c|c|c|c|}
\hline Variable & $\begin{array}{c}\text { Type of test } \\
(c, t, n)\end{array}$ & ADF test value & $1 \%$ & $5 \%$ & $10 \%$ & Result \\
\hline$C X$ & $(c, t, 3)$ & -2.071 & -4.356 & -3.595 & -3.233 & Non-stationary \\
\hline$D(C X, 1)$ & $(c, t, 3)$ & -2.789 & -4.324 & -3.581 & -3.225 & Non-stationary \\
\hline$D(C X, 2)$ & $(c, 0,3)$ & -6.580 & -3.711 & -2.981 & -2.630 & Smooth \\
\hline$C Y$ & $(c, t, 3)$ & -0.833 & -4.324 & -3.581 & -3.225 & Non-stationary \\
\hline$D(C Y, 1)$ & $(c, t, 3)$ & -2.605 & -4.324 & -3.581 & -3.225 & Non-stationary \\
\hline$D(C Y, 2)$ & $(0,0,3)$ & -5.420 & -2.653 & -1.954 & -1.610 & Smooth \\
\hline
\end{tabular}

Note: The test type $(\mathrm{c}, \mathrm{T}, \mathrm{N})$ represents a constant entry, a time trend, and a lag order in the ADF test. The lag order is judged by the minimum value of test results of AIC and SC.

Table 4. Results of the cointegration regression of the development of China's port Industry $(\mathrm{CX})$ and economic Growth $(\mathrm{CY})$

\begin{tabular}{|c|c|c|c|c|}
\hline Variable & Coefficient & Std. Error & t-Statistic & Prob. \\
\hline$C Y$ & 0.609 & 0.178 & 3.428 & 0.0021 \\
\hline$A R(1)$ & 1.795 & 0.205 & 8.747 & 0.0000 \\
\hline$A R(2)$ & -0.779 & 0.223 & -3.491 & 0.0018 \\
\hline
\end{tabular}

Note: $\mathrm{CY}$ is the independent variable, $\mathrm{CX}$ is the dependent variable

Table 5. Test results for unit root of $\varepsilon_{\mathrm{t}}$

\begin{tabular}{|c|c|c|c|c|c|c|}
\hline $\begin{array}{c}\text { Variabl } \\
e\end{array}$ & $\begin{array}{c}\text { Type of } \\
\text { test }(c, t, \\
n)\end{array}$ & $\begin{array}{c}\text { ADF } \\
\text { test } \\
\text { value }\end{array}$ & $1 \%$ & $5 \%$ & $10 \%$ & Result \\
\hline$\varepsilon_{t}$ & $(c, 0,3)$ & $\begin{array}{c}-4.41 \\
2\end{array}$ & $\begin{array}{c}-3.70 \\
0\end{array}$ & $\begin{array}{c}-2.97 \\
6\end{array}$ & $\begin{array}{c}-2.62 \\
7\end{array}$ & $\begin{array}{c}\text { Smoot } \\
h\end{array}$ \\
\hline
\end{tabular}

From the test results of Table 5 , it can be seen that $\varepsilon_{\mathrm{t}}$ is I (0), that is $\varepsilon_{\mathrm{t}}$ is stationary. Therefore, it is assumed that $\mathrm{CX}$ and $\mathrm{CY}$ are cointegration, that is, $\mathrm{CX}$ and $\mathrm{CY}$ have long-term equilibrium relationship.

Then, the Grainger causality test is performed on CX and CY, and the results are shown in table 6 .

Table 6. Grainger causality test of $\mathrm{CX}$ and $\mathrm{CY}$

\begin{tabular}{|c|c|c|c|}
\hline Null Hypothesis: & Obs & F-Statistic & Prob. \\
\hline CY does not Granger Cause CX & 28 & 4.051 & 0.031 \\
\hline CX does not Granger Cause CY & & 10.956 & 0.001 \\
\hline
\end{tabular}

Note: The lag order is 2 .

It can be seen from the test results of Table 6 that $\mathrm{CY}$ is the Granger cause of $\mathrm{CX}$, that is, the economic growth of China is the cause of the development of the port industry, the same, CX is CY's Granger cause, that is, China's port industry development is the Granger cause for the economic growth.From the relationship between the two, we can see that the development of port industry and economic growth of China are interrelated and mutual causality.

\subsection{Impulse Response and Variance Solution of Port Industry and Economic Growth}

We can know the causal relationship between the port industry and economic growth through the cointegration analysis, but how the change of the unit variable affects the disturbance of the whole system through its intrinsic relation, and how the change of the response of each variable to these disturbances needs to establish the VAR model to do the impulse response analysis on the port industry and economic growth [13], finally the long-term relationship between variables can be determined. The autoregressive model of $\mathrm{P}$-order vectors is:

$$
\begin{gathered}
y_{t}=A_{1} y_{t-1}+A_{2} y_{t-2}+\cdots+A_{p} y_{t-p}+B_{1} x_{t-1}+ \\
\cdots+B_{r} x_{t-r}+\varepsilon_{t}
\end{gathered}
$$

In the formula, $y_{t}$ is $m$-dimensional endogenous variable vector, $\mathrm{x}_{\mathrm{t}}$ is $\mathrm{d}$-dimensional exogenous variable vector, $\mathrm{p}, \mathrm{r}$ is respectively the delay order number of endogenous variable and exogenous variable, $A_{1}, \ldots, A_{p}$ and $B_{1}, \ldots, B_{r}$ is the parameter matrix to be estimated, and $\varepsilon_{\mathrm{t}}$ represents the error vector.

(1) VAR model test. Firstly, the data is preprocessed. Since the natural logarithmic transformation of the data does not change the original cointegration relationship and can linearize its trend, it eliminates the heteroscedasticity phenomenon in the time series. Therefore, the natural numerical value of all data is obtained to enhance the linearization trend of the data and eliminate the variance. The AR root test results of the VAR model are shown in Figure 5.

Inverse Roots of AR Characteristic Polynomial

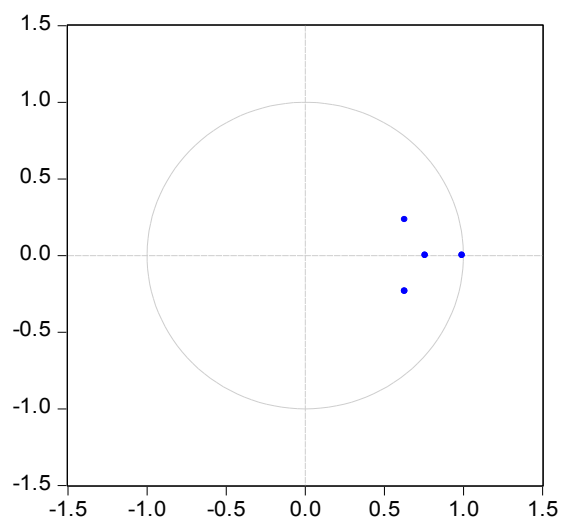

Fig. 5. AR root test result of VAR model

It can be seen from Fig. 5 that the AR root is all within the unit circle, that is, it can be concluded that the VAR model is stable and can carry out impulse response analysis on GDP and throughput of major coastal ports of China.

(2) Impulse response analysis. The impulse response analysis describes the magnitude of the influence of the current value of the model endogenous variable on the 
perturbation term plus the impact of the unit standard deviation and the other endogenous variables through the dynamic structure of the model. GDP (CY) impulse response to major coastal port throughput (CX) of China is shown in Fig.6 and the impulse response of major coastal port throughput (CX) to GDP (CY) of China is shown in Fig. 7.

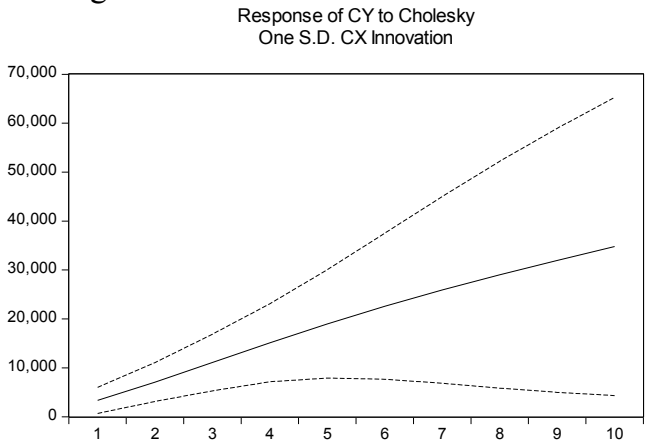

Fig. 6. Impulse response of GDP (CY) to major coastal port throughput $(\mathrm{CX})$ of China

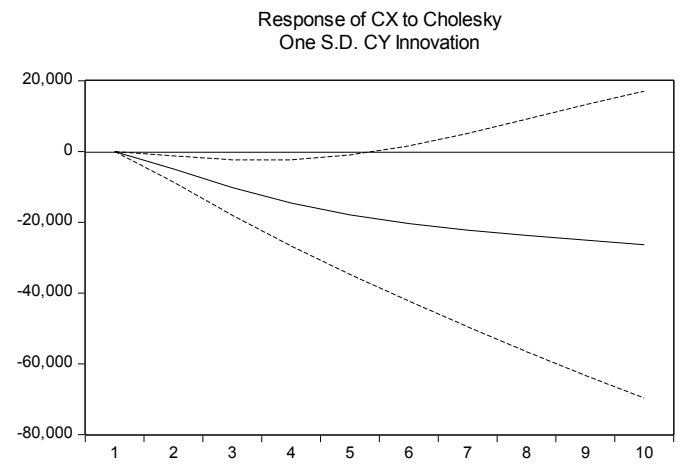

Fig. 7. Impulse response of major coastal port throughput (CX) to GDP (CY) of China

It can be seen from the results of impulse response that China's GDP has a positive shock response on the throughput of major coastal ports, and the response is increasing over time. The main port throughput of our country has a negative shock response on GDP, and the response of negative response will increase over time, but after the 7 th period, it gradually becomes more balanced.

(3) Variance Decomposition. Variance Decomposition method ${ }^{[14]}$ is to decompose the fluctuation of endogenous variables into the contribution of the variable shocks in the system, and then analyze the importance of different shocks. The variance decomposition of the throughput of the main coastal ports in China and GDP is done through Eviews8, and the results are shown in table 7.
Table 7. Variance Decomposition of throughput in major coastal ports in China (CX)

\begin{tabular}{|c|c|c|c|}
\hline \multicolumn{4}{|c|}{ Variance Decomposition of CX: } \\
\hline Period & S.E. & CX (\%) & $C Y(\%)$ \\
\hline 1 & 8497.317 & 100.000 & 0.000 \\
\hline 2 & 18004.070 & 92.423 & 7.577 \\
\hline 3 & 29002.770 & 84.668 & 15.332 \\
\hline 4 & 40680.200 & 79.369 & 20.631 \\
\hline 5 & 52507.380 & 75.999 & 24.000 \\
\hline 6 & 64222.410 & 73.903 & 26.097 \\
\hline 7 & 75743.080 & 72.623 & 27.375 \\
\hline 8 & 87095.950 & 71.874 & 28.126 \\
\hline 9 & 98368.580 & 71.464 & 28.536 \\
\hline 10 & 109679.300 & 71.274 & 28.726 \\
\hline
\end{tabular}

The result of variance decomposition in table 7 shows that the throughput of major coastal ports in our country is only affected by its own fluctuation in the $1^{\text {th }}$ period, starting from the $2^{\text {nd }}$ period, the GDP has an effect on the throughput of the main coastal ports, and the influence gradually increases over time, but at the beginning of the $7^{\text {th }}$ period, it gradually tends to balance, affecting about $28 \%$.It can be seen that the development of China's maritime industry is largely affected by economic growth If the trend of China's economic growth can be effectively analyzed, it can guide the development of maritime industry.

The variance decomposition of China's GDP (CX) is shown in table 8 .

Table8. Variance Decomposition of China's GDP(CX)

\begin{tabular}{|c|c|c|c|}
\hline \multicolumn{4}{|c|}{ Variance Decomposition of CY: } \\
\hline Period & S.E. & $C X$ & $C Y$ \\
\hline 1 & 7424.40 & 20.215 & 79.785 \\
\hline 2 & 11564.54 & 45.839 & 54.161 \\
\hline 3 & 16092.19 & 71.177 & 28.823 \\
\hline 4 & 22274.60 & 83.200 & 16.800 \\
\hline 5 & 30139.08 & 85.090 & 14.915 \\
\hline 6 & 39244.54 & 83.295 & 16.705 \\
\hline 7 & 49167.87 & 80.857 & 19.143 \\
\hline 8 & 59615.40 & 78.703 & 21.297 \\
\hline 9 & 70413.62 & 77.011 & 22.989 \\
\hline 10 & 81479.98 & 75.743 & 24.257 \\
\hline
\end{tabular}

It can be seen from the result of variance decomposition of table 8 that the growth of GDP in China is affected by the throughput of major coastal ports in the $1^{\text {th }}$ period, and the influence reaches $79.8 \%$, which is greater than its own influence, however, the impact of the throughput of the major coastal ports was gradually reduced before the $7^{\text {th }}$ period, and the $7^{\text {th }}$ period was affected by $80.9 \%$, and after the $8^{\text {th }}$ period, the impact of the throughput of the major coastal ports began to increase. Thus, it can be judged that China's port industry and economic growth affect and promote each other in the process of development. 


\section{Conclusion and Analysis}

From the analysis of cross-spectrum results, we can see that there is a certain correlation between the development of port industry and economic growth. In the coherence spectrum generated by time series, the correlation between the throughput and GDP of the main coastal ports in China is at a higher level in the period of 3 to 4 years, while the correlation between the two is at a lower level than in the period of 10 years. The result of this kind of data is inseparable from the development of our country's planned economy system, in formulating the economic growth plan, the state should make an adjustment in the 5 year cycle. Under the state macro control, China's economic development will develop in a long time and be in a good direction. At the same time, under the guidance of the national policy, the development of China's port industry will also be coordinated with economic development in a short period of time. Therefore, in a 5-year cycle, the correlation between the development of China's port industry and economic growth is higher, however, in the long period of port industry and economic growth in the development of the time axis, the development of port industry is less affected by endogenous variables and exogenous variables compared with the economic growth, while economic growth can be pulled through a variety of channels, except for the promotion of port industry. Therefore, in the long period of consistency analysis, the relationship between port industry development and economic growth will be in a low state. China's economic growth in the short cycle is ahead of the development of the port industry. In the phase spectrum formed by the throughput index of the main coastal ports in China and GDP index, the growth of our economy will lead to the development of the port industry from 0.8 years to 1.1 years in the short period of 3-4 years. However, due to the different response time of economic growth and port industry to external shocks, the development of China's port industry will be ahead of economic growth in a short period of time. The reasons for this result are closely related to the development characteristics of our country. In the long-term economic development of our country, due to the scarcity of capital, the development of many industries in our country is limited by the financial difficulties. The port industry as a capital investment, investment return cycle of a long industry, is also subject to a lot of restrictions. Therefore, in the whole fluctuation process of the development of China's port industry, the overall development of it will lag behind the growth of China's economy.

The results of dynamic econometric analysis show that China's economic growth and the development of port industry are Granger causes, which are interrelated and mutually reinforcing. It can be seen from the results of the impulse response that China's economic growth has made a positive response to the impact of the development of port industry. Meanwhile, the response gradually increases over time. However, China's port industry has made a negative impact on economic growth, and the negative response will increase over time, and eventually will gradually become more balanced.
The results of variance decomposition show that China's port industry will be affected by greater economic growth in the long-term development process, and this effect will gradually tend to a stable state, the impact level is about $28 \%$, meanwhile, the development of economic growth in the short term will be closely affected by the port industry, the impact of the port industry on the volume of foreign trade completion will outweigh the factors of economic growth, but in the long run, this effect will gradually weaken, and the influence of endogenous variables of economic growth will gradually increase. It can be judged that China's port industry and economic growth are in a state of mutual influence and promotion in the process of development.

\section{Acknowledgment}

This paper is supported by the major projects of the National Social Science Fund (13 \& ZD170), the New Century Excellent Talents Support Program of the Ministry of Education (NCET-13-0701) and the "Thirteen Five" Research Project of Dalian Maritime University (3132016361)

\section{References}

1. Ma Zheng-bing.The Application of Fourier Series and Fourier Transform in the Derivation of Two Formulas [J]. Examweekly 5 (2015)

2. Gu Zu-kai.Study on the Relationship between Bulk Cargo Price and Freight Price Based on Cross Spectral Analysis [D]. Master 's Degree Thesis of Dalian Maritime University (2016)

3. Duan Kai-yu, Yin Shi-shu, Fu Ming .An Empirical Study on the Cross - Spectrum of the Price Discovery Function of Grain Futures in China [J]. Statistics\& Decision 1 (2005)

4. $\mathrm{Wu} \mathrm{Xu}$, Wang Rui-jun, $\mathrm{Hu}$ Si-ji.Cross-spectra Analysis on Relationship between Railway Transportation and National Economy [J].China Soft Science 5 (2016)

5. Yu Jie, Han Xiao.Analysis on Price Volatility Cycle of Chinese Raw Milk Based on X12 Seasonal Adjustment Method and H-P Filter Model [J]. China Dairy Cattle 18 (2014)

6. Li Dong-sheng, Liu Xiao-le.New Characteristics of Pig Price Fluctuation in China - An Empirical Analysis Based on HP and BP Filtering [J].Rural Economy 6 (2015)

7. Nie Qiao-ping, Zhang Xiao-dong .Research on LM Statistics of Joint Hypotheses for ADF Unit Root Test [J] .Statistical Research 2 (2007)

8. Mo Da-long.Modeling time series with ADF validation [J].Times Finance 7 (2010)

9. Zhao Xue-yu .Research on the Relationship between World Trade and World Shipping Based on Co integration Theory [D].Master 's Degree Thesis of Dalian Maritime University (2013)

10. $\mathrm{Xu}$ Guo-xiang.Statistical Forecasting and Decision Making (Fourth Edition)Shang Hai: Shanghai University of Finance \& Economics Press (2012) 
11. Kong Fan-wen, Cai $\mathrm{Xu}, \mathrm{Yu}$ Miao.Analysis and Application of Granger 's Causality Test Model [J]. Journal of Shenyang Jianzhu University Natural Science 2 (2010)

12. Wu Wen-qing, Liu Chao .A Study on the Fluctuation of Purchase and Sale of State-owned Grain Enterprises in China - Based on Wavelet Analysis and Granger's Causality Test [J].Economic Theory and Business Management 10 (2001)

13. Zhong Xiao-jun.A Study on the Relationship between Direct Investment and China's Import and Export Trade - Impulse Response Function and Variance Decomposition Method Based on VAR Model [J].Statistical education 6 (2009)

14. Zhang Rong, Zhang Cai-qin.House price index, CPI and social consumption level -- An Interpretation Based on impulse response and variance decomposition [J].Academic Forum 10 (2015)

15. B Büttner.Effectiveness versus Efficiency: Growth Accelerating Policies in a Model of Growth without Scale Effect[J], German Economic Review 7 (3), 297-316 (2006)

16. GLASS,A., X.WU.Intellectual Property Rights and Quality Improvement[J]. Journal of Development Economics 82,393-415(2007) 